\title{
EFFECT OF ALTERNATIVE FUELS ON THE BURNING PROCESSES IN THE SPARK IGNITION COMBUSTION ENGINE
}

\author{
Andrej Chríbik, Marián Polóni, Branislav Ragan, Rastislav Toman
}

Slovak University of Technology in Bratislava, Faculty of Mechanical Engineering, Námestie slobody 17,812 31 Bratislava, andrej.chribik@stuba.sk ${ }^{1}$, marian.poloni@stuba.sk ${ }^{2}$, branislav.ragan@stuba.sk ${ }^{3}$,rastislav.toman@stuba.sk ${ }^{4}$

Keywords: spark ignition engine, alternative gaseous fuels, pressure analysis, mass fraction burned

\begin{abstract}
The presented article discusses the use of alternative gaseous fuels (a mixture of natural gas with hydrogen and a mixture of natural gas with carbon dioxide) in spark-ignition engine LGW 702 and their impact on the nature of combustion. An analysis of pressure in the combustion chamber has revealed that increasing volume of hydrogen in the mixture of hydrogen with natural gas leads to shorter ignition delay and shorter overall duration of combustion. On the other hand, increasing proportion of carbon dioxide in the mixture of carbon dioxide with natural gas causes an extension of ignition delay as well as extension of total duration of combustion. The nature of combustion significantly affects the resulting parameters of the combustion engine.
\end{abstract}

\section{INTRODUCTION}

The task to secure energy sources to power internal combustion engines forces the researchers to test various types of alternative fuels derived from sustainable energy sources. One possibility is to utilize hydrogen mixed with natural gas as a transitional fuel to the expected hydrogen era. Such a mixture is generally marked H2NGXX with indicated volumetric percentage of hydrogen in the fuel mixture. Natural gas (approximately $98 \%$ methane) as a fuel is currently commonly used in transportation, either in gaseous or liquid state. A synergy between the mentioned fuels can bring a mixture of higher flammability. An increase in the proportion of hydrogen in the gas mixture brings about shorter delay of ignition. With increasing proportion of hydrogen the rate of spreading of the flame also increases which reduces the burning time at which the release of heat energy becomes faster. The presence of hydrogen in the fuel favourably influences production of emissions as with an increase in the proportion of hydrogen in the fuel the atomic ratio of hydrogen to carbon increases, which results in a decrease of emissions containing carbon (carbon dioxide, carbon monoxide and unburned hydrocarbons). On the contrary, the formation of water and nitrogen oxides is higher, as these are related to higher combustion temperatures $[1,2]$.

The utilization of biogas (a mixture of methane and carbon dioxide) is welcome mainly in stationary combustion engines for cogeneration units, while abroad there is also a widespread use of biogas in urban transport [3]. The biogas composition varies, depending on the parameters of manufacturing processes and the type and composition of the raw material [4]. The utilization of biogas in combustion engines is environmentally beneficial, especially in terms of ever increasing consumption of renewable fuels and it also contributes to lower environmental burdens. 


\section{EXPERIMENTAL MEASUREMENTS}

The following experimental measurements were made on the spark-ignition engine Lombardini LGW 702 designated for a micro-cogeneration unit [5]. It is a twin-cylinder watercooled internal combustion engine with the displacement of $686 \mathrm{~cm}^{3}$ and a compression ratio of 10.5:1. The mixture was prepared with the help of a mixer with a diffuser. The change of ignition advance of the mixture was adjusted manually. The experimental measurements were carried out in one single revolution mode $\left(1500 \mathrm{~min}^{-1}\right)$ at full load. To monitor the pressure in the combustion chamber during the dynamic pressure, a spark plug with an integrated piezoelectric sensor from Kistler was used. The correction of the measured pressure towards the absolute pressure was performed with the help of a reference value of pressure present in the manifold (measured with a piezo-resistive pressure sensor) with the position of the piston in the BDC at the end of the intake stroke. The processing of the data from the pressure sensor, crankshaft position and from the ignition signal was carried out with the help of a program created in Matlab. To analyse the combustion process a one -zone zero - dimensional thermodynamic model was used. The model solves the equation of the Law of conservation of energy in the phase when the valves are closed. The progress of fuel burning was determined on the basis of the measured pressure by Rassweiler Withrow method. This method states that the measured pressure is a combination of the increase of pressure caused by the combustion process with the increase of pressure caused by volumetric change. The beginning and end of the combustion process was determined by the change in entropy. The measured pressure can be a basis for evaluation of the overall character of the running of the engine (cycle variation). The character is often expressed as so called coefficient of variation $(\mathrm{COV})$. The coefficient of variation is calculated as:

$$
\operatorname{cov}=\frac{\sqrt{\frac{1}{n-1} \sum_{i=1}^{n} x_{t}-\bar{x}}}{\lambda 100} \text { [\%]. }
$$

where $n$ is the total number of cycles, $x_{i}$ is the $i$ - th value of the monitored cycle parameter and $\bar{x}$ is the arithmetic average of the monitored parameter out of the given number of cycles. The actual reduction of cycle variation contributes to increases of power under the same fuel consumption. The following Table 1 gives the basic properties of the mixture of hydrogen and natural gas and mixtures of natural gas and carbon dioxide. With the increasing proportion of hydrogen the net calorific value increases, while the fuel density decreases. Hence, the resulting energy density of the fuel also decreases. Conversely, with the increasing ratio of carbon dioxide the net calorific value decreases and the density of the fuel mixture increases. The air to fuel ratio considerably drops with increasing volume of carbon dioxide in the mixture with natural gas.

Table 1: Basic physical - chemical properties of fuel mixtures

\begin{tabular}{|l|c|c|c|c|c|c|}
\hline Parameter & Unit & NG & H2NG25 & H2NG50 & CO2NG25 & CO2NG50 \\
\hline NG in mixture & {$[\%$ vol. $]$} & 100 & 75 & 50 & 75 & 50 \\
\hline Lower heating value & {$\left[\mathrm{kJ} \cdot \mathrm{kg}^{-1}\right]$} & 48729 & 51551 & 56467 & 25968 & 13415 \\
\hline Density & {$\left[\mathrm{kg} \cdot \mathrm{m}^{-3}\right]$} & 0,693 & 0,541 & 0,389 & 0,977 & 1,261 \\
\hline Molar mass & {$\left[\mathrm{kg} \cdot \mathrm{kmol}^{-1}\right]$} & 16,69 & 13,02 & 9,35 & 23,52 & 30,35 \\
\hline Air to fuel ratio & {$\left[\mathrm{kg} \cdot \mathrm{kg}^{-1}\right]$} & 16,98 & 17,66 & 18,86 & 8,97 & 4,62 \\
\hline
\end{tabular}


The following Figure 1 shows the curves of mass portion of the fuel burned (MFB) as depending on the angle of rotation of the crankshaft for the mixtures H2NG0 and H2NG50 after 195 consecutive cycles. The course shows that because of admixing of hydrogen, the period of time in the first phase of combustion gets shorter approximately by $3.2^{\circ} \mathrm{CA}$, and also the total duration time of burning of the mixture gets shorter by $12.9^{\circ} \mathrm{CA}$. In Figures c), d) there is the progress of mass ratio of burned fuel for natural gas and biogas $\left(50 \% \mathrm{CH}_{4}\right.$ and $\left.50 \% \mathrm{CO}_{2}\right)$. Under the given ignition advance, the increase in the proportion of carbon dioxide causes a considerable dispersion of individual curves. With growing volume of $\mathrm{CO}_{2}$ the ignition delay increases on average by $6^{\circ} \mathrm{CA}$. The end of the combustion when burning biogas is lifted more to the expansion stroke. The average total burning period was prolonged by approximately $57 \%$. From the images a), c) it can also be seen how the angle of ignition advance influences the nature of combustion of the mixture when under operation on natural gas the difference of angle of advance is $5^{\circ} \mathrm{CA}$. Somewhat early ignition advance contributed to more concentrated dispersion of combustion in each phase of combustion, at the cost of reduced performance parameters.


Figure 1: Mass fraction of the burned fuel (MFB) depending on the position of crankshaft for the next mixtures: a) H2NGO, b) H2NG50, c) CO2NGO, d) CO2NG50, (conditions: number of cycles : 195, full load, stoichiometric ratio, revolutions: $1500 \mathrm{~min}^{-1}$, angle of ignition advance for mixture H2NG: $\varphi_{\text {ign }}=32^{\circ} \mathrm{CA}$ BTDC and for mixture CO2NG: $\varphi_{\text {ign }}=37^{\circ} \mathrm{CA}$ BTDC)

The following Figure 2 shows the values of the position of crankshaft, at gradually burned $5 \%, 10 \%, 50 \%$ and $90 \%$ of fuel (MFB), depending on the ratio of hydrogen in the mixture with natural gas. As seen in the previous figure, addition of hydrogen causes to shorten the 
combustion time in each phase of combustion. The period between the ignition advance and burning of $5 \%$ mass fraction of fuel equals the value $20.7^{\circ} \mathrm{CA}$ for natural gas. For the mixture H2NG50 this period becomes reduced by $24 \%$ to $15.8^{\circ} \mathrm{CA}$. The value of the angle between the ignition advance and the moment in which $50 \%$ of fuel is burned will have the value for natural gas $33.3^{\circ} \mathrm{CA}$. When burning the mixture $\mathrm{H} 2 \mathrm{NG} 50$, this period was reduced by $22 \%$ to $26^{\circ} \mathrm{CA}$. The most visible period of burning can be seen at the end of the combustion process, when the slowing down period of burning the mixture $\mathrm{H} 2 \mathrm{NG} 50 \mathrm{KH}$ is $2.9^{\circ} \mathrm{CA}$, which is only $36 \%$ of the period of afterburning of natural gas $\left(7.7^{\circ} \mathrm{CA}\right)$.

During the combustion analysis, a parallel analysis was performed on dispersed positions in which the above mentioned phases of burning of mass fractions of fuels were reached. On the basis of the coefficient of variation (equation 1) for a given angular position an analysis was performed to cover various mixtures of natural gas with hydrogen from a sample of 195 consecutive cycles. The analysis shows that the coefficient of variation for a position under $5 \%$ MFB for natural gas has the value of $0.33 \%$; for the mixture H2NG50, this coefficient is $0.25 \%$. Gradual burning of fuel causes a greater dispersion between particular mixtures.

In case of $50 \%$ proportion of the fuel burned, the coefficient of variation related to the crankshaft position when burning natural gas is $0.56 \%$ and when burning the mixture H2NG50 the value is $0.40 \%$. The largest observed difference between coefficients has been observed for the position of the crankshaft, in which $90 \%$ of the fuel has been burned ( COV for H2NG0 $=0.87$ $\%$ and $\mathrm{COV}$ for $\mathrm{H} 2 \mathrm{NG} 50=0.36 \%)$.

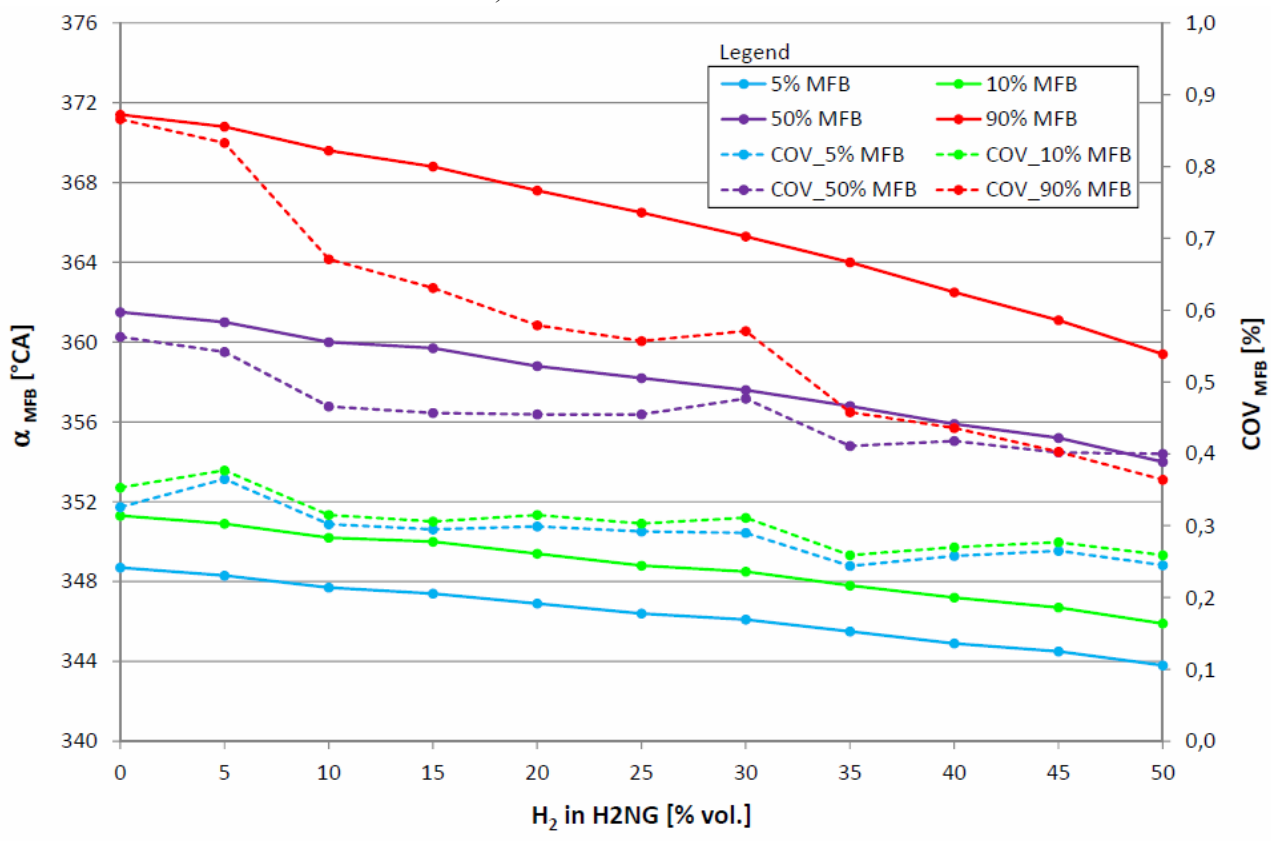

Figure

2: Average values of the position of crankshaft $\left(\alpha_{M F B}\right)$ at 5\%, 10\%, 50\% and 90\%-mass of fuel burned (MFB) and the coefficients of variation $\left(C O V_{M F B}\right)$ related to them as depending on composition of fuel (a mixture of natural gas with hydrogen), (conditions: number of cycles 195 , full load, stoichiometric ratio, revolutions: $1500 \mathrm{~min}^{-1}$, angle of ignition advance $\varphi_{\text {ign }}=32^{\circ} \mathrm{CA}$ 
This analysis shows that blending of hydrogen into natural gas leads to stabilization of combustion, especially in the final phase of combustion in the cylinder, when because of added hydrogen to natural gas the inter-cyclic variability is at very low levels. In the last Figure 3 there are the values of the crankshaft position for the burned $5 \%, 10 \%, 50 \%$ and $90 \%$ of the fuel (MFB) as depending on the proportion of carbon dioxide in the mixture with natural gas. By increasing the proportion of carbon dioxide the period of combustion in each phase of the combustion gets longer. The period between the moment of ignition advance and the burning of 5 $\%$ mass of fuel has for the natural gas the value $20.5^{\circ} \mathrm{CA}$. When burning the mixture CO2NG50, this period will be extended by $1.5^{\circ} \mathrm{CA}$. The value of the angle between the ignition advance and burning $50 \%$ of fuel equals the value $32.6^{\circ} \mathrm{CA}$ for natural gas. When burning the mixture CO2NG50 this period is extended by $16 \%$ to $37.7^{\circ} \mathrm{CA}$. A significant difference between the burning periods for particular mixtures occurs at the end of combustion. The period from the ignition advance till the moment when $90 \%$ of fuel is burned has the value $41.8^{\circ} \mathrm{CA}$ for natural gas and for the mixture $\mathrm{CO} 2 \mathrm{NG} 50$ the value is $52.6^{\circ} \mathrm{CA}$. The slow gradual finish of afterburning of the fuel (position between $90 \% \mathrm{MFB}$ and the end of combustion) for the mixture CO2NG50 has the value up to $18.2^{\circ} \mathrm{CA}$. The analysis of the coefficient of variation of the position of crankshaft for particular percentages of MFB, out of 195 consecutive cycles for various compositions of the mixture $\mathrm{CO} 2 \mathrm{NG}$, shows that the coefficient of variation of the position of crankshaft at $5 \% \mathrm{MFB}$ has the value $0.37 \%$. For the mixture CO2NG50 the coefficient of variation of the position of crankshaft is $1.37 \%$. The largest observed scattering of position relates to $90 \%$ of fuel burned. Natural gas has the value of the coefficient of variation $0.69 \%$ and the mixture CO2NG50 has this value $2.46 \%$. From the above-mentioned analysis it can be concluded that the increasing volumetric proportion of carbon dioxide in natural gas leads to destabilization of combustion, especially in the final phase of mixture burning and the burning takes place deep in the expansion stroke.

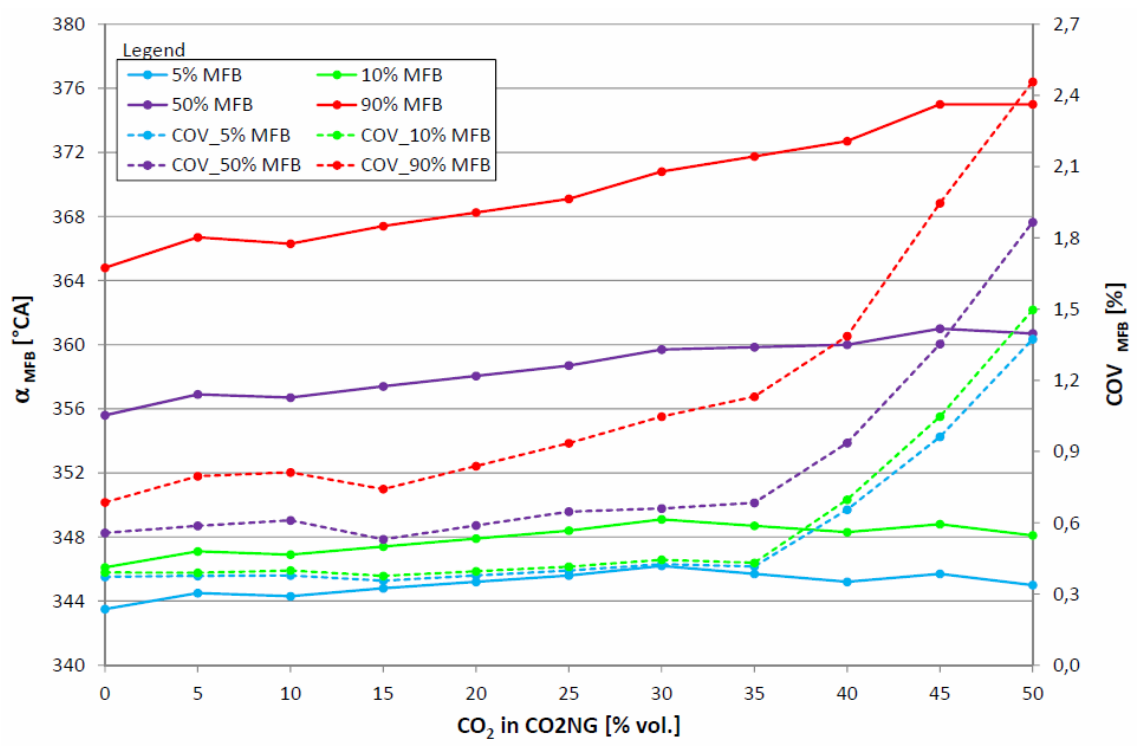

Figure 3: The average values for the position of crankshaft $\left(\alpha_{M F B}\right)$ for 5\%, 10\%, 50\% and 90\% mass of fuel burned (MFB) and their related coefficients of variation $\left(C O V_{M F B}\right)$ as depending on the composition of fuel (mixture of natural gas with carbon dioxide), (conditions: number of cycles 
195, full load, stoichiometric ratio, revolutions: $1500 \mathrm{~min}^{-1}$, angle of ignition advance $\varphi_{\text {ign }}=37^{\circ}$ CA BTDC)

\section{CONCLUSIONS}

The information on the course of combustion and the coefficients of variation related to crankshaft position provide a valuable insight into the stability of combustion, which is a key factor able to optimize ignition advance for various fuel compositions. The following points briefly evaluate the results of the analysis of the combustion mixture of natural gas with hydrogen and the mixture of natural gas with carbon dioxide that has been aimed at the combustion course.

The results are as follows:

- shortening of the ignition delay on average by $30 \%$ when compared mixtures H2NG0 with H2NG50,

- increasing volume of hydrogen shortens the period of beginning and end of combustion while the operating conditions stay unchanged,

- adding of hydrogen to the gas mixture reduces the total time of combustion in each of its stages (burning shorter on average by $23 \%$ to $29 \%$, when comparing mixtures H2NG0 with H2NG50),

- with increasing mass volume of hydrogen, the coefficient of variation in the position of the crankshaft $5 \%, 10 \%, 50 \%$ or $90 \%$ mass proportion of fuel burned decreases,

- there occurs extension of ignition delay on average by $50 \%$ for compared mixtures CO2NG0 and CO2NG50,

- increasing proportion of carbon dioxide extends the period between the beginning and end of combustion, while the operating conditions stay unchanged,

- adding carbon dioxide to the mixture extends the total period of combustion in each phase of the process (extending the combustion period on average by $7 \%$ to $26 \%$, for compared mixtures CO2NG0 with CO2NG50),

- increasing proportion of carbon dioxide increases the coefficient of variation for the position of crankshaft at $5 \%, 10 \%, 50 \%$ or $90 \%$ mass proportion of fuel burned.

\section{REFERENCES}

[1] KAHRAMAN, N., et al.: Investigation of combustion characteristics and emissions in a sparkignition engine fuelled with natural gas-hydrogen blends, Internal Journal of Hydrogen Energy, 2009, Volume 34, pp. $1026-1034$.

[2] AKANSU, S.O., et al.: Experimental study on a spark ignition engine fuelled by methane-hydrogen mixtures, International Journal of Hydrogen Energy, 2007, Volume 32, pp. 4279 - 4284.

[3] Biogas upgrading and utilization. Energy from biological conversion of organic waste. (ieabiogas.net/files/daten-redaction/download/public-task37/Biogas\%20upgrading.pdf)

[4] LASTELLA, G., et al.: Anaerobic digestion of semi-solid organic waste : biogas production and its purification, Energy Conversion and Management, 2002, Volume 43, pp. 63 - 75.

[5] POLÓNI M., KÁLMAN P., LACH J., SMIEŠKO Š., LAZAR L., KUNC P., JANČOŠEK L.: Micro-cogeneration Unit with Variable-Speed Generator. International Scientific Event "Power Engineering 2010”. May 18-20, 2010, Tatranské Matliare, High Tataras, Slovak Republic. Volume of abstracts of the $9^{\text {th }}$ International Scientific Conference: Energy-Ecology-Economy (EEE) 2010. 22 pages, ISBN 978-80-89402-11-9.

\section{ACKNOWLEDGEMENTS}


SCIENTIFIC PROCEEDINGS 2013, Faculty of Mechanical Engineering, STU in Bratislava

Vol. 21, 2013, pp. 19-18, DOI: 10.2478/stu-2013-0004

This work was supported by the Slovak Research and Development Agency under the contract No. APVV-0015-12 and under the contract No. APVV-0090-10. 